\title{
Erratum to: A Segment-Based SACK Scheme for TCP Over the Error-Prone Links
}

\author{
Lin Cui · Xin Cui · Woo Jin Lee
}

Published online: 16 October 2010

C) Springer Science+Business Media, LLC. 2010

\section{Erratum to: Wireless Pers Commun DOI 10.1007/s11277-010-0028-2}

The Acknowledgment in the original publication is incorrect. It should read "This project is supported by Tianjin Research Program of Application Foundation and Advanced Technology (10JCYBJC26100).”

The online version of the original article can be found under doi:10.1007/s11277-010-0028-2.

L. Cui $(\bowtie)$

Tianjin University of Technology and Education, Tianjin, China

e-mail: cuilin.academic@gmail.com

X. Cui

Shandong University at Weihai, Weihai, China

e-mail: chlgms@sdu.edu.cn

W. J. Lee

Kyungpook National University, Daegu, Korea

e-mail:wjlee@knu.ac.kr 